\title{
La renuncia a las garantías del juicio oral por medio del procedimiento abreviado en Chile
}

\author{
Waiver of the judgment's guarantees through the \\ abbreviated procedure in Chile
}

Cristián Riego ${ }^{1}$

Profesor Universidad Diego Portales - Santiago/Chile

cristian.riego@udp.cl

orcid.org/0000-0002-7013-1976

\begin{abstract}
RESUMEN: El artículo describe como están reguladas las garantías básicas del juicio oral el en Código Procesal Penal chileno de 2000. Al mismo tiempo muestra como en ese Código se estableció la posibilidad de renunciar a esas garantías por parte del imputado mediante el procedimiento abreviado, aunque esta posibilidad se regulo de un modo muy limitado. Finalmente se describe como una ley reciente amplio sustantivamente el uso y los incentivos para el procedimiento abreviado en los delitos de criminalidad común dividiendo el sistema chileno en dos subsistemas, uno donde el juicio oral sigue siendo central y otro en el que tendera a volverse excepcional a favor de la negociación.
\end{abstract}

Palabras-clave: juicio oral; procedimiento abreviado; debido proceso.

AвstRAct: The paper describes the defendant rights in the new Chilean Criminal Procedure Code of 2000. Also describes how the Code allowed in a very limit-

1 Abogado, titulado de la Universidad de Chile. LL.M. (Master en Derecho) en la Universidad de Wisconsin, 1997. Abogado Investigador de la Comisión Nacional de Verdad y Reconciliación, 1990 y 1991. Director del equipo técnico redactor del Código Procesal Penal Chileno y la ley del Ministerio Público 1994 a 2000. Profesor Titular de la Escuela de Derechos de la Universidad Diego Portales. Ha sido profesor e investigador visitante en las universidades de Yale y Columbia en los EEUU y Warwick en el Reino Unido. Es autor de varios libros y artículos en el tema del proceso penal y ha desarrollado proyectos de investigación en numerosos países de América Latina en el mismo campo. Se desempeñó como Director Ejecutivo del Centro de Estudios de Justicia de las Américas, CEJA desde 2008 hasta 2013. 
ed expression the possibility of the waiver of the judgment guarantees through the abbreviated procedure. Finally it describes a new law that expanded substantially the use and the incentives for negotiation just in property offences. This last development has divided the Chilean criminal procedure in two subsystems, one in which the oral trial is still the center of the procedure and another in which the trial will becomes exceptional.

KEYWORDS: oral trial; due process; plea-bargaining.

Sumario: Introducción; 1. Las garantías del juicio en el Código Procesal Penal; 2. El procedimiento abreviado en el Código Procesal Penal; 3. La nueva regulación en la Ley 20.931 de 2016; Consideraciones finales; Referencias.

\section{INTRODUCCIÓN}

El nuevo Código Procesal Penal Chileno dictado el año 2000 introdujo como gran innovación el establecimiento del juicio oral y público como expresión central y paradigmática de las garantías de debido proceso. Por medio de ese mecanismo se pretendió dar vigencia a derechos tan importantes como la publicidad del juzgamiento, el ejercicio amplio de la defensa, la imparcialidad de los juzgadores y la presunción de inocencia.

De manera algo paradojal, ese mismo Código estableció la posibilidad de evitar la forma de juzgamiento que el mismo proclamó por medio del establecimiento del procedimiento abreviado ${ }^{2}$, que constituye la renuncia al juicio oral y su reemplazo por una forma de juzgamiento simplificada basada en el reconocimiento de los hechos por parte del imputado y la lectura de la carpeta de la investigación del Fiscal

2 Esta paradoja parece ser una tendencia bastante generalizada en todo el mundo: "The irony of this development (towards oral and public trials), is that, with the greater ability of the defense to achieve an acquittal, or make the criminal procedure more lengthy and cumbersome, the more the system turns, informally or formally, to trial-shortening guilty pleas, confession bargaining or other consensual procedural modes" (THAMAN, Stephen. A Typology of Consensual Criminal Procedure, an Historical and Comparative Perspective on the Theory and Practice of Avoiding the Full Criminal Trial. 
por parte de juez. Esta fórmula se tradujo en el llamado procedimiento abreviado para los delitos con penas de más de quinientos cuarenta días regulado en el artículo 406 y siguientes y, para los delitos de penas inferiores, en la aceptación de responsabilidad en procedimiento simplificado, regulada en el artículo 395.

La recepción del procedimiento abreviado en el Código del año 2000 se hizo teniendo especialmente en cuenta las críticas que suelen dirigirse al modelo del plea bargaining en los Estados Unidos. Dichas criticas plantean que este favorece la practica masiva de la renuncia al juicio y sus garantías por medio del establecimiento de fuertes incentivos consistentes en la gran diferencia entre las penas elevadas que se arriesgan en el juicio oral, frente a las reducciones que pueden obtenerse por medio de una negociación con el fiscal.

Debido a lo anterior, el procedimiento abreviado en el Código Procesal Penal chileno tuvo una expresión limitada, se admitió solo para penas no superiores a cinco años y se cuidó de no establecer la posibilidad de diferencias de penas significativas que pudiesen constituir incentivos muy fuertes para la renuncia al juicio.

Recientemente se ha introducido, para un grupo limitado de delitos, una nueva ley destinada a favorecer el uso del procedimiento abreviado por medio de la generación de fuertes incentivos para que el imputado renuncie al juicio. Por medio de esas normas especiales, los fiscales están en condiciones de ofrecer a los imputados diferencias muy sustantivas de penas, esas ofertas pueden resultar muy difíciles de resistir y pueden derivar en que el juicio oral pase a ser una especie de lujo que pocos podrán permitirse.

El presente trabajo pretende mostrar como ha evolucionado la noción de centralidad del juicio oral en el Código Procesal Penal desde

In: THAMAN, Stephen (ed.). World Plea Bargaining. Consensual Procedures and the Avoidance of the Full Criminal Trial. Durham: Carolina Academic Press, 2010. p. 392). En la misma linea Langer habla del Plea Bargaining como "el caballo de troya del sistema adversarial" (LANGER, Maximo. From Legal Transplants to Legal Translations: The globalization of Plea Bargaining and the Americanization Thesis in Criminal Procedure Trial.In: THAMAN, Stephen (ed.). World Plea Bargaining. Consensual Procedures and the Avoidance of the Full Criminal Trial. Durham: Carolina Academic Press, 2010. p. 46). 
el año 2000 a la fecha actual. En una primera sección mostraremos de manera resumida la forma en que el Código del 2000 reguló las garantías del juicio oral. En una segunda parte mostraremos cuales fueron las características del procedimiento abreviado en el Código y como se pretendió que este tuviera una expresión limitada para evitar la instalación de un modelo de aplicación masiva de sentencias condenatorias basadas en incentivos de rebajas de penas.

En una tercera parte analizaremos la nueva regulación e intentaremos proyectar como debiera funcionar, validando la hipótesis de que se puede generar, para un segmento que abarca casi la mitad del conjunto del sistema, una lógica semejante a la de los Estados Unidos en cuanto a que los incentivos consistentes en grandes diferencias de penas reducirán significativamente el acceso de los imputados al juicio.

\section{Las garantías del juicio en el Código Procesal Penal}

El Código Procesal Penal dictado el año 2000 estableció en Chile el juicio oral como la base fundamental del sistema de garantías. Esta idea se expresa con toda claridad en su artículo primero, que proclama: "Toda persona tiene derecho a un juicio previo, oral y público, desarrollado en conformidad con las normas de este cuerpo legal”.

Los primeros artículos del Código plantean un catálogo de garantías básicas que el juicio pretende realizar, como la presunción de inocencia en el Artículo 4, o el derecho a la defensa artículo 8. Pero son las normas que regulan el juicio y la prueba las que dan cuenta más específicamente del modo en que el Código entiende las garantías básicas que pretendió establecer.

Para explicar las garantías del juicio en Código Procesal Penal Chileno es necesario distinguir dos niveles diferentes de análisis, que además corresponden al desarrollo temporal de la discusión sobre el juicio oral durante el periodo de su discusión y diseño. En un primer nivel se encuentra una noción de garantías básicas muy ligadas a la ritualidad de la oralidad. En una primera etapa de la discusión sobre el Código se entendía que el objetivo principal de la introducción de la oralidad estaba vinculada al reconocimiento de los valores políticos del sistema 
republicano al interior del sistema de justicia penal. La pretensión original estaba vinculada al establecimiento del juicio como un acto público donde las partes en conflicto pudiesen diferenciarse claramente, en especial el carácter imparcial del juzgador y la función acusatoria del fiscal. También se pretendió afirmar la posibilidad de que el imputado y su abogado pudiesen expresarse con completa autonomía y la garantía de ser oídos en todo momento por el juzgador. Asimismo, se buscaba afirmar que la prueba se presentara de manera inmediata y pudiera ser escuchada, observada y analizada por todos los intervinientes y el público. También se pretendía que las decisiones finales solo obedecieran a la información presentada en el juicio. Todas estas cuestiones deben entenderse como parte del propósito de abandonar el sistema inquisitivo tradicional chileno en el que ninguna de estas condiciones se producía y respecto del cual el juicio oral representaba una gran innovación.

En este primer nivel, las normas más importantes son las que regulan de los llamados principios del juicio oral, que están en los artículos 282 a 291 del Código. Estas son una serie de normas que pretenden asegurar la noción de lo que es un juicio en el contexto de una cultura jurídica completamente ajena a esa noción y al interior de la cual todas las normas procesales tendían a leerse y a aplicarse bajo la lógica del expediente escrito. Los artículos 282, 283 y 284 proclaman el principio de continuidad del juicio, regulan muy restrictivamente las posibilidades de suspensión y exigen la presencia ininterrumpida de los jueces en las audiencias, todo con el fin de evitar a toda costa que el juicio se transforme en una serie de trámites separados cuyas actas luego puedan ser leídas por el juez. Los artículos 285 y 286 por su parte exigen la presencia ininterrumpida del imputado y su defensor para efectos del ejercicio de sus facultades. Los artículos 289 y 291, por su parte, regulan detalladamente la publicidad del juicio y el uso obligatorio de la oralidad para el desarrollo de todas las actividades del mismo. En la misma línea anterior, es decir la de asegurar una ritualidad nueva consistente con los ideales republicanos que el Código pretendía realizar, una de las normas generales sobre la prueba contenida en el artículo 296 proclama el principio de que la prueba a ser valorada por los jueces es la que se rinde durante el juicio y en consecuencia se someta a todas las condiciones establecidas en su regulación. 
En un segundo nivel, y que corresponde a una segunda etapa en la discusión del proyecto del Código chileno, se encuentran otras normas que desarrollan algunas garantías de manera bien especifica. Se trata de normas vinculadas principalmente al tratamiento de la prueba y expresan en nuestra opinión una comprensión más profunda del juicio, ya no solo como un rito republicano sino como una oportunidad de que el imputado ejercite su defensa de modo intensivo. Se trata de reconocer que el derecho a la defensa supone que el imputado debe estar en condiciones de cuestionar a fondo la prueba de cargo. Esta actividad del imputado opera en su propio beneficio pero también en el del sistema, el que de esta manera minimiza así la posibilidad de cometer errores.

Este segundo tipo de normas está también vinculado a la creciente influencia en Chile del modelo angloamericano de la justicia penal, la que no estuvo muy presente a los inicios de la discusión del Código pero que fue importante en sus etapas finales y lo ha seguido siendo como lo acredita la ley 20.931 que comentaremos más adelante.

Probablemente la más notoria de las normas a las que nos venimos refiriendo es la que introduce en el sistema chileno la regla, típica del sistema adversarial anglosajón, del examen y contraexamen. El artículo 330 permite el desarrollo de un contrainterrogatorio por medio de preguntas sugestivas, esto es la posibilidad de confrontar al declarante con otras versiones por medio de afirmaciones que realiza el abogado y que el declarante debe aceptar o negar. Este método es entendido por el Código, y por la cultura legal derivada de él, como la expresión más importante del derecho a defensa ${ }^{3}$.

Recoge además el Código otras normas que son complementarias de la anterior como es la del artículo 329 que prohíbe el reemplazo de la comparecencia de un declarante por la lectura de una declaración prestada previamente, esto es, se pretende evitar que la

3 Ejemplos del gran desarrollo que estas nociones han tenido en Chile son los numerosos trabajos que han elaborado acerca de sus consecuencias. Por ejemplo: BAYTELMAN, Andres; DUCE, Mauricio. Litigación Penal y Prueba. Santiago: Universidad Diego Portales, 2004; VIAL, Pelayo. Técnicas y Fundamentos del Contraexamen en Proceso Penal Chileno. Santiago: Librotecnia, 2016. 
confrontación de la prueba sea eludida por medio de su reemplazo por documentos que den cuenta de declaraciones previas del testigo o perito. Mas especifica todavía es la regla del artículo 334 que prohíbe la incorporación a juicio de los registros de la policía o del Ministerio Público, es decir con esto se termina de proscribir el uso del expediente de investigación como fuente de prueba, lo que solía ser el método fundamental en el sistema inquisitivo tradicional. Otra norma muy importante es la del artículo 332 que permite el uso excepcional de declaraciones previas para la confrontación de un testigo que comparece al juicio. Esta regla es otro instrumento central destinado al ejercicio de la defensa entendida como facultad de confrontación de la prueba de cargo.

Las regulaciones del ejercicio de la defensa en juicio por medio de la confrontación de la prueba están complementadas con otras normas destinadas a hacerlas practicables. Nos referimos fundamentalmente a aquellas destinadas a permitir que el imputado tenga acceso a anticipado al conocimiento de las pruebas que el fiscal pretende presentar con el fin de preparar el ejercicio de la confrontación. Ellas son fundamentalmente la del artículo 259 letra f), que obliga al fiscal la indicación precisa de las pruebas de que se ha de vales en el juicio y la del artículo 182, que otorga a la defensa pleno acceso a los registros de la investigación del fiscal con el objetivo de preparar la confrontación de la prueba durante el juicio.

En síntesis, el Código Procesal Penal buscó establecer en Chile un juicio oral que permitiera el ejercicio de las garantías básicas del debido proceso. Para lograr ese propósito procuró en primer lugar instalar con mucha fortaleza las ritualidades básicas por medio de normas muy estrictas, pero además busco desarrollar de manera bastante específica el ejercicio de la confrontación entendiendo que este constituye el elemento fundamental del ejercicio de la defensa. Estas regulaciones a su vez han dado lugar a un amplio desarrollo de prácticas, comentarios legales, actividades de capacitación y jurisprudencia de los diversos tribunales, lo que las ha hecho adquirir una enorme centralidad práctica en el sistema de justicia chileno, que ha pasado a recepcionar al juicio oral como la expresión central de su funcionamiento y expresión fundamental de las garantías del imputado. 


\section{El procedimiento abreviado en el Código Procesal Penal ${ }^{4}$}

Como ya hemos indicado, el propio Código Procesal Penal que lo consagró introdujo la posibilidad de evitar al estado la necesidad de llevar adelante un juicio oral y público, permitiendo que el imputado renunciara a todos los derechos que se realizan en él y admitiera un juzgamiento con mucha menos garantías por la vía del procedimiento abreviado regulado en el Título III del libro cuarto del Código Procesal Penal, o por su correlato en el procedimiento simplificado para los casos de penas inferiores a quinientos cuarenta y un días de privación de libertad, consistente en el reconocimiento de responsabilidad en regulado en el Artículo 395.

La base de dicha renuncia está constituida por un acuerdo entre el imputado y el fiscal por el cual el primero acepta los hechos de la acusación y el juzgamiento basado en los antecedentes de la investigación realizada por el fiscal, y este último fija una pena que constituye el máximo de la condena que puede ser establecida por el juez.

Cuando se tomó la decisión de proceder de esta manera se estaba siguiendo la tendencia generalizada de las legislaciones de la época ${ }^{5}$. Pero además se tuvo en cuanta la información disponible que llamaba la atención acerca de los riegos involucrados en permitir la renuncia al juicio oral y sus garantías e cuanto este camino se pudiera convertir en una formula extorsiva destinada a presionar a los imputados para obtener su renuncia al juicio y generar así la posibilidad de una vulneración de las garantías básicas que el Código pretendía establecer ${ }^{6}$.

4 Mi conocimiento de la discusión que se produjo en torno al procedimiento abreviado proviene de mi participación como director del equipo que redactor del Proyecto de Código Procesal Penal que fue enviado por el ejecutivo al Congreso y luego como asesor del ministerio de justicia en toda la tramitación del Código. Además: RIEGO, Cristián. El Procedimiento Abreviado. In: CAROCCA, Alex (org.). Nuevo Proceso Penal. Santiago: Jurídica Cono Sur, 2000. p. 205-226; RIEGO, Cristian. El Procedimiento Abreviado en Chile. In: MAIER, Julio B. J.; BOVINO, Alberto (comps.) El Procedimiento Abreviado. Buenos Aires: Del Puerto, 2001. p. 453-475.

5 HORVITZ, María Inés; LOPEZ, Julián. Derecho Procesal Penal Chileno. Tomo II. Santiago: Jurídica de Chile, 2014. p. 503.

6 Un buen ejemplo de las aprehensiones que a la época del Código generaba el procedimiento abreviado la expresa Julio Maier, sin duda el autor más in- 
En consecuencia, la fórmula que se utilizó estuvo destinada a permitir que el imputado que no tuviera una discrepancia sustantiva con los cargos formulados en su contra pudiera optar por una forma de juzgamiento más sencilla obteniendo algunas ventajas limitadas, las que en ningún caso deberían constituirse en un incentivo o una presión tan fuerte como para que quienes realmente se opongan sustantivamente a la acusación se vieran motivados a renunciar al juicio y a las garantías que el ofrece. ${ }^{7}$

La limitación más importante que se estableció en el Código al procedimiento abreviado consistió en restringir su aplicación a la aplicación de sanciones relativamente bajas por medio de establecer que solo podían ser juzgadas por esta vía las acusaciones en que la pena solicitada por el fiscal no excediera los cinco años de privación de libertad. Esta limitación tiene una enorme importancia porque en la práctica no solo restringe la posibilidad de que se establezcan penas de larga duración por la vía de la negociación sino que favorece el uso de este procedimiento para penas sustitutivas a la privación de libertad que son de general aplicación en el sistema chileno a las penas no superiores a cinco años tratándose de personas sin condenas penales anteriores.

A pesar de que no contamos con datos precisos al efecto, no parece demasiado aventurado afirmar que en la práctica en nuestro sistema de justicia penal, hasta antes de la vigencia de la ley 20.931 no era

fluyente sobre los Códigos que se dictaron en diversos países latinoamericanos en ese período: "el orgullo que sin modestia siento al observar como "prendieron"ciertas instituciones de aquel proyecto de 1986 (...) no se reproduce en este caso. Aquí he dado pie, sin una reflexión política y de fondo, a una institución, en principio extraña a nuestra cultura jurídica, que se expande y amenaza con derribar los pilares de nuestra comprensión de la pena estatal y del procedimiento necesario para imponerla" (MAIER, Julio. Prologo. In: MAIER, Julio; BOVINO, Alberto (comps). El Procedimiento Abreviado. Buenos Aires: Del Puerto, 2001).

7 Un ejemplo de las múltiples aprehensiones y resistencias que en la comunidad legal chilena genera la posibilidad de una condena basada en un procedimiento consensuado en: DEL RIO, Carlos. Proceso Penal consenso de las partes y enjuiciamiento jurisdiccional. Santiago: Librotecnia, 2009. Tambien: HORVITZ, María Inés; LOPEZ, Julián. Derecho Procesal Penal Chileno. Tomo II. Santiago: Jurídica de Chile, 2014. p. 503. Quienes además exponen algunas de las criticas más importantes a estas formas de juzgamiento provenientes de la literatura europea y de los EEUU. 
común que se condenara en procedimiento abreviado a penas que se traduzcan en encarcelamientos efectivos. La gran mayoría de los condenados por esta vía lo son medidas alternativas a la privación de libertad. Tampoco estableció el sistema chileno premios o rebajas especiales de penas para quienes acepten la renuncia a juicio, formula que es común en otras legislaciones que se tuvieron a la vista en la elaboración del Código Procesal Penal. ${ }^{8}$

En general nos parece posible sostener que el sistema del Código Procesal Penal no estuvo orientado a incentivar la aceptación de renuncia al juicio por la vía de una negociación basada en diferencias entre la sanción que es posible establecer en el juicio y aquella que el fiscal fija como máxima en el procedimiento abreviado. Es claro que alguna diferencia puede existir, pero ella no resulta demasiado significativa dado que los fiscales no pueden renunciar a la persecución ni a una parte de ella de acuerdo con el principio de legalidad. En la práctica las diferencias de penas que los fiscales pueden ofrecer para incentivar la renuncia al juicio se limitan más bien a fijar las penas máximas que se ubiquen en los rangos inferiores de los marcos establecidos por la ley, a favorecer la aceptación por parte del juez de una circunstancia atenuante, a no alegar alguna circunstancia agravante, o a recomendar el uso de una medida alternativa o sustitutiva a la privación de libertad, cuestiones que por lo demás los jueces pueden resolver autónomamente sin la petición del fiscal si es que sus fundamentos aparecen probados. ${ }^{9}$

8 Por ejemplo, en el sistema Italiano la aceptación del procedimiento abreviado por parte del imputado se premia con una rebaja de un tercio de la pena que el juez deba imponer. Artículo $442 \mathrm{~N}^{\circ} 2$ del Código de Procedimiento Penal Italiano.

9 En un texto anterior, cercano a la vigencia del inicio del nuevo sistema procesal penal, sostuve que si bien el CPP pretendió regular de modo restrictivo la posibilidad de la rebaja de penas como un incentivo a la renuncia al juicio, existían posibilidades de que por la vía informal los fiscales pudieran generar esos incentivos. No obstante, y aunque no conozco estudios empíricos que permitan acreditar esto de manera precisa, mi impresión es que ello ha ocurrido solo en el sentido de que en algunos casos los fiscales favorecen sustantivas, en general orientadas a alcanzar marcos penales que permitan la aplicación de medidas alternativas a la privación de libertad: RIEGO, Cristian. El Procedimiento Abreviado en Chile. In: MAIER, Julio B. J.; BOVINO, Alberto (comps.) El Procedimiento Abreviado.Buenos Aires: Del Puerto, 2001. 
Por otra parte el diseño del procedimiento mismo también está orientado a no favorecer la negociación directa sobre el monto de la pena dado que el juez no basa su decisión en el acuerdo entre las partes. A pesar de la aceptación de los hechos por parte del imputado, se requiere que el juez valore la prueba y dicte una sentencia, la que incluso podría ser absolutoria. ${ }^{10}$ De este modo la ley ha procurado evitar un modelo de justicia estrictamente consensual en el que la condena tiene su origen directamente desde el acuerdo de partes, reemplazándolo más bien por un modelo en el que el acuerdo establece una forma distinta de juzgamiento en la que tanto la decisión condenatoria como el monto de la pena son decisiones entregadas al juez y este debe tomarlas con base en las pruebas allegadas y en las reglas legales.

A todas las limitaciones enumeradas anteriormente se suma la existencia de la norma del Artículo 409 del CPP que obliga al juez a cautelar de manera específica la voluntariedad del acuerdo, pudiendo rechazarlo si es que estima que el imputado no ha actuado voluntariamente o con la adecuada información. Dicha obligación del juez aparece especialmente fortalecida en cuanto el articulo 414 inciso segundo del CPP permite que el ejercicio de ese control pueda ser objeto de revisión por la vía del recurso de apelación que recae sobre la sentencia dictada en el procedimiento abreviado, es decir una vez que el procedimiento abreviado ha concluido, probablemente con una sentencia condenatoria, todavía puede el imputado cuestionar la voluntariedad del acuerdo por el cual renunció a su derecho a un juicio.

En síntesis, nos parece posible afirmar que la recepción de la posibilidad de renuncia al juzgamiento por medio de un juicio oral y su reemplazo por un sistema simplificado basado en un acuerdo entre las partes, fue admitida en el Código Procesal Penal del año 2000 de modo muy limitado tanto en cuanto al monto de las penas susceptibles de ser impuestas por esta vía, a la falta de un margen importante de discrecionalidad para el fiscal que favoreciera su poder negociador y en cuanto a preservar para el juez facultades importantes que le permiten controlar

10 FALCONE, Diego. La Absolución en el Procedimiento Abreviado. Revista de Derecho de la Pontificia Universidad Católica de Valparaíso, vol. XXVI, p. 363378, 2005. 
tanto las condiciones del pacto entre las partes, la suficiencia de la prueba de cargo y la legalidad de la pena, antes de dar lugar a una condena.

\section{LA NUeVA REguLACIÓN eN LA Ley 20.931 de 2016}

El juicio oral tiene ya diecisiete años de presencia en Chile y parece razonable sostener que más allá de innumerables defectos en su práctica, sus ritualidades básicas se encuentran bastante asentadas en el país. No obstante, uno de los problemas que se ha venido planteando es que el volumen de juicios es bastante elevado ${ }^{11}$. Esta situación ha generado la percepción de que el gasto de recursos humanos y materiales en los juicios es muy alto y de que en muchos casos no está justificado dado que en una porción importante de los casos no hay una verdadera contradicción de los cargos por parte de la defensa.

Dichos cuestionamientos han sido especialmente importantes en los casos vinculados a lo que podríamos llamar la criminalidad común, que suele ser la principal fuente de atención por parte de los medios de comunicación y de la política nacional. Frente a ese tipo de planteamiento se han esbozado diversas iniciativas de reforma una de las más importantes de las cuales se ha traducido en la ley 20.931 del año 2016.

Dicha ley contiene una cantidad muy significativa de reformas específicas destinadas a mejorar la persecución penal de los delitos que se considera que afectan de modo significativo la seguridad pública. Desde el punto de vista de las políticas de seguridad pública se ha estimado que de la gran cantidad delitos definidos por la ley, es solo un número limitado de ellos los que producen el efecto de afectar de manera predominante la seguridad de la población tanto en términos objetivos como subjetivos. Es decir, unos pocos tipos penales concentran una gran cantidad de hechos delictivos y estos a su vez contribuirían de manera decisiva al aumento del temor de la población. Debido a esto las

11 De acuerdo con los datos del Ministerio Público en el año 2007, a dos años de la entrada en vigencia del nuevo sistema en todo el país, se desarrollaron un total de 6.086 juicios orales. El año 2010 esa cifra aumentó a 10.175 juicios. En 2013 la cifra fue de 9.135 y en 2016 de 11.705 juicios por año. 
estrategias estatales destinadas a mejorar la seguridad suelen concentrarse en los delitos incluidos en esa categoría, la que suele ser definida como delitos que afectan la seguridad pública o delitos de mayor connotación social ${ }^{12}$.

Es a partir de una definición como la descrita que esta ley ha buscado fortalecer la persecución penal respecto de un grupo de delitos específicos $^{13}$. Se trata de los delitos contra la propiedad más tradicionales vinculados a lo que se conoce comúnmente como la delincuencia común, esto es los delitos de hurto y las diferentes formas de robos descritas en nuestra legislación penal ${ }^{14}{ }^{15}$.

12 Aparentemente uno de los primeros usos del criterio de discriminación descrita y la expresión "delitos de mayor connotación social" corresponde al documento llamado: Diagnostico de la Seguridad Ciudadana en Chile, Ministerio del Interior, Mayo de 2004. p. 19. En ese texto se plantea la necesidad de focalizar la atención en algunos delitos y aunque no se hacen definiciones precisas se focaliza la atención en algunos delitos contra la propiedad. Otros documentos que utilizan esta aproximación varían en cuanto a los delitos que se toman en cuenta pero siempre con un énfasis en los delitos contra la propiedad. Por ejemplo, la encuesta de victimización Paz Ciudadana- Adimark pregunta por los delitos de robo solamente (<http://www.pazciudadana.cl/ wp-content/uploads/2017/01/ipc-2016-version-conferencia-120117.pdf >). Por su parte la encuesta nacional de victimización ENUSC que realiza el gobierno incluía tradicionalmente los delitos de hurto, robo y lesiones, a los que a partir del año 2015 se agregaron otras categorías de delitos como son los daños a vehículos o viviendas, algunos delitos económicos, los delitos cibernéticos, el delito de amenazas y una categoría caracterizada como incivilidades y violencias en los barrios (<http://www.seguridadpublica.gov.cl/ media/2016/05/ENUSC-2015.pdf $>$ ).

13 El mensaje de la ley hace referencia al aumento en los delitos de mayor connotación social registrado por las encuestas de victimización y al hecho de que dentro de esa categoría los delitos contra la propiedad representan una proporción muy mayoritaria. Mensaje $N^{\circ} 1167-362 /$ del Presidente a de la República a la cámara de diputados, Santiago, 23 de enero de 2015.

14 Los delitos incluidos en este nuevo régimen son los delitos comprendidos en los Párrafos 1 a 4 bis, con excepción de aquellos contemplados en los artículos 448, inciso primero, y 448 quinquies, y del artículo 456 bis A, esto es, todos los robos y hurtos con excepción del hurto de hallazgo simple y el de apropiación de plumas, pelos, crines, cerdas, lanas o cualquier elemento del pelaje de animales ajenos y con la adición del delito de receptación de bienes producto de robos y hurtos.

15 La identidad que esta ley plantea entre afectación a la seguridad pública y delitos de robo y hurto parece problemática tanto por la exclusión de ciertos 
La modificación más sustantiva está constituida por un conjunto de cambios específicos cuya interacción simultanea genera en nuestra opinión un escenario completamente nuevo para el funcionamiento del procedimiento abreviado en un espacio que representa una porción muy significativa del total de delitos de que conoce el sistema.

Este cambio tiene tres componentes legales principales. El primero de ellos está constituido por una modificación del sistema de determinación de las penas aplicables a los delitos de hurto y a todas las modalidades de robo establecidas en Código Penal Chileno. El sistema general de determinación de penas consiste en que el Código Penal asocia a cada tipo delictivo unas penas cuya duración está condicionada por un marco relativamente amplio de tiempo dentro del cual el juez debe determinar la duración específica a partir de algunos criterios que la ley establece. Pero el marco de duración establecido por la ley puede cambiar por la existencia de diversas circunstancias atenuantes o agravantes que están descritas pormenorizadamente por la ley y cuya existencia debe el juez determinar de modo preciso en el fallo. De este modo, la existencia de circunstancias atenuantes o agravantes puede hacer que la pena final se encuentre fuera del marco establecido por la ley para el tipo penal.

La nueva ley cambia la fórmula descrita respecto de los delitos abarcados por ella, en el sentido de impedir que las atenuantes y agravantes permitan al juez modificar el marco penal. Es decir, respecto de esos delitos, hurtos y robos, el efecto de las atenuantes o agravantes que puedan existir opera solo para permitir al juez determinar la pena al interior del marco. En el caso de tratarse de personas reincidentes, además del efecto descrito, se establece que la determinación de la pena

delitos como por la inclusión de otros. En cuanto a la exclusión, los propios instrumentos usados para medir la victimización han ido ampliando el conjunto de situaciones que se incluyen en esta categoría por su contribución a la inseguridad, de este modo se trata de abarcar diversos hechos violentos que generan un efecto de temor en la población como las peleas con resultados de lesiones o los disparos de armas de fuego. Por otra parte, en cuanto a la inclusión, el tipo penal de hurto incluye muchos incidentes que en realidad tienen una peligrosidad baja y que difícilmente contribuyen al temor ciudadano de manera importante, como son los hurtos de cosas de poco valor en el comercio, por ejemplo. 
operará solo en la mitad superior del marco penal, es decir la reincidencia produce el efecto de excluir del ámbito de determinación de la pena la mitad inferior del marco ${ }^{16}$.

El segundo componente del cambio está constituido por una norma que otorga un incentivo extraordinario para el imputado que, tratándose de los mismos delitos a los que se aplican las nuevas reglas de determinación de las penas, consienta en renunciar a su derecho a un juicio oral y convenga en un procedimiento abreviado o acepte la responsabilidad en un procedimiento simplificado. El premio establecido por la ley consiste en la posibilidad de rebaja de un grado en la pena, respecto de la que corresponda a partir de la aplicación de los criterios de determinación establecido en el componente descrito anteriormente ${ }^{17}$.

Finalmente, el tercer componente está constituido por la ampliación, solo para los delitos a los que se refiere esta nueva regulación, de la aplicabilidad del procedimiento abreviado el que pasa de un límite

16 Nuevo artículo 449: "Para determinar la pena de los delitos comprendidos en los Párrafos 1 a 4 bis, con excepción de aquellos contemplados en los artículos 448, inciso primero, y 448 quinquies, y del artículo 456 bis A, no se considerará lo establecido en los artículos 65 a 69 y se aplicarán las reglas que a continuación se señalan: $1^{\mathrm{a}}$. Dentro del límite del grado o grados señalados por la ley como pena al delito, el tribunal determinará la cuantía de la pena en atención al número y entidad de las circunstancias atenuantes y agravantes concurrentes, así como a la mayor o menor extensión del mal causado, fundamentándolo en su sentencia. $2^{\mathrm{a}}$. Tratándose de condenados reincidentes en los términos de las circunstancias agravantes de los numerales 15 y 16 del artículo 12, el tribunal deberá, para los efectos de lo señalado en la regla anterior, excluir el grado mínimo de la pena si ésta es compuesta, o el mínimum si consta de un solo grado".

17 Intercálase en el artículo 407 el siguiente inciso cuarto, nuevo, pasando el actual a ser inciso quinto: "Sin perjuicio de lo establecido en los incisos anteriores, respecto de los delitos señalados en el artículo 449 del Código Penal, si el imputado acepta expresamente los hechos y los antecedentes de la investigación en que se fundare un procedimiento abreviado, el fiscal o el querellante, según sea el caso, podrá solicitar una pena inferior en un grado al mínimo de los señalados por la ley, debiendo considerar previamente lo establecido en las reglas 1a o 2a de ese artículo". Agrégase en el artículo 395 el siguiente inciso segundo: "En los casos de los delitos señalados en el artículo 449 del Código Penal, el fiscal podrá solicitar una pena inferior en un grado al mínimo de los señalados por la ley, debiendo considerar previamente lo establecido en las reglas 1a y 2 a del artículo 449 del mismo cuerpo legal”. 
de cinco años de privación de libertad como pena máxima a uno de diez años ${ }^{18}$.

El conjunto de estos tres componentes produce un efecto muy acentuado sobre el modo en que los delitos contra la propiedad son tratados por el sistema de justicia penal a partir de la vigencia de la nueva ley. En la práctica, la ley en cuestión supone un aumento muy sustantivo en las penas que efectivamente han de ser determinadas por los jueces. Por otra parte ese aumento puede ser compensado, a lo menos parcialmente, por medio de la renuncia al juicio y el acuerdo en el procedimiento abreviado. El efecto descrito es especialmente intenso en los delitos que tienen una pena superior a los cinco años debido a que bajo ese umbral existe la posibilidad de la aplicación de una medida alternativa a la pena privativa en libertad siempre que el imputado no tenga condenas previas. En esos casos, solía ocurrir que el juez rebajara la pena por aplicación de atenuantes y otorgara una medida alternativa a la privación de libertad que permite evitar el encierro. De acuerdo con la nueva ley, el único camino que queda disponible al imputado que es candidato a la medida alternativa a la privación de libertad es el de acceder a la rebaja de pena por medio de la renuncia a juicio.

Llevando la situación a un ejemplo concreto, supongamos que se trata de un imputado por robo con intimidación que no tiene condenas previas. La pena establecida por la ley fija un marco entre cinco años y un día a quince años. Anteriormente, dependiendo de las circunstancias específicas, esa persona podía tener la expectativa de una rebaja de pena por la atenuante de la irreprochable conducta anterior quedando por ejemplo con una pena de tres años y un día a cinco años. En ese rango de pena quedaba en una buena posición para obtener una medida alternativa a la privación de libertad y no ir a la cárcel. Con la nueva regulación, las atenuantes que pueda tener, incluyendo la irreprochable

18 Añádese, en el inciso primero del artículo 406, luego de la frase "no superior a cinco años de presidio o reclusión menores en su grado máximo”, la expresión: "no superior a diez años de presidio o reclusión mayores en su grado mínimo, tratándose de los ilícitos comprendidos en los párrafos 1 a 4 bis del título IX del Libro Segundo del Código Penal y en el artículo 456 bis A del mismo Código, con excepción de las figuras sancionadas en los artículos 448 , inciso primero, y 448 quinquies de ese cuerpo legal”, antecedida de un punto y coma. 
conducta anterior no le permiten bajar la pena de los cinco años y un día y por lo tanto deberá cumplir una de privación de libertad efectiva. La única manera de evitarlo será la de renunciar al juicio y aceptar el procedimiento abreviado. En consecuencia, la diferencia de pena como incentivo para renunciar al juicio será de cinco o más años de privación de libertad. Si va a juicio arriesga una condena por ese tiempo, si accede al procedimiento abreviado puede acceder a una pena de cumplimiento alternativo, es decir, no será privado de libertad.

En el caso de las personas que tiene condenas anteriores el elemento que acrecienta la diferencia de pena está en la norma que suprime el grado mínimo o el mínimum para el cálculo de la sanción específica. Si tomamos el mismo ejemplo anterior del robo con intimidación pero de una persona reincidente, la pena establecida en la ley abarca dos grados, de cinco años y un día a diez años y de diez años y un día a quince años. La nueva regla obliga a suprimir el grado más bajo con lo que el sujeto podría ser condenado en juicio oral a una pena mínima de diez años y un día. Con la renuncia a juicio se puede obtener una reducción de un grado con lo que la pena mínima que el fiscal puede ofrecer es de cinco años y un día. De nuevo en este segundo caso la diferencia de pena es importante y sería de cinco años de privación de libertad.

El análisis del efecto de la nueva regulación que podemos hacer a estas alturas es solo hipotético y además aparece muy simplificado porque solo toma en cuenta la variable del monto de las penas que podrían ser aplicadas de acuerdo con la nueva ley. En la realidad existen varios otros factores que condicionan las negociaciones que eventualmente conducen a un procedimiento abreviado. Uno sin duda muy importante es el de la prisión preventiva, el hecho de que el imputado se encuentre en prisión preventiva u otras medidas cautelares importantes puede ser un gran incentivo a la aceptación de un procedimiento abreviado, especialmente si la oferta del fiscal permite anticipar una pena susceptible de una medida alternativa a la privación de libertad. En relación con esta variable, nos parece claro que la ley 20.931 debiera jugar un papel importante en cuanto a favorecer el otorgamiento de prisión preventiva u otras cautelares intensas para los delitos a los que afecta. Lo anterior especialmente debido a que diversas reformas legales han 
condicionado cada vez más intensamente a los jueces para la dictación de esa medida en los delitos con penas altas ${ }^{19}{ }^{20}$.

La ley 20.931 ha realizado modificaciones que sin constituir cambios estructurales aparentes a las instituciones del sistema procesal penal representan, a lo menos respecto de un aspecto muy importante del mismo lo que podríamos llamar un cambio de modelo. Esto es, el legislador ha establecido un conjunto de reglas que fijan nuevas condiciones y nuevos incentivos para los actores del sistema de justicia penal que muy probablemente los llevarán a una práctica muy diferente a la vigente en cuanto a la aplicación del procedimiento abreviado en los delitos contra la propiedad abarcados por ella. Todo este nuevo esquema obedece en realidad a un nuevo marco ideológico para la compresión de la función del procedimiento abreviado en los delitos de robo y hurto.

En el segmento de delitos regulados de manera especial por la ley comentada se ha dispuesto un alza sustantiva de las penas efectivamente aplicables para los delitos de hurto y robo. No obstante, dicha alza puede compensarse a lo menos en parte por medio de la renuncia al juicio. Al mismo tiempo se ha ampliado el rango de pe-

19 En especial el inciso cuarto del artículo 140 letra c) introducido por la ley 20.253 de 2008 que establece una especie de presunción de peligrosidad para varias hipótesis entre las que se encuentra la de tener el delito una pena de crimen estabecida en la ley. Sobre esto: DUCE, Mauricio; RIEGO, Cristian. La Prisión Preventiva en Chile: Análisis de los cambios legales y su impacto. Santiago: Ediciones Universidad Diego Portales, 2011.

La propia ley 20931 contiene una norma que continúa la tendencia de favorecer el uso de la prisión preventiva. Se trata de una modificación del inciso segundo del Artículo 149 del Código Procesal Penal. La ley 20.253 de 2008 introdujo en ese inciso una regla que estableció que tratándose de ciertos tipos penales, la resolución del juez de garantía que no otorgara o revocara la prisión preventiva no daría lugar a la libertad del imputado mientras no fuera confirmada por la Corte de Apelaciones. Tres de esos delitos están entre los afectados por nuestro análisis, los de los artículos 433, 436, 440 del Código Penal. La ley 20.931 modifica esa regla en varios sentidos siendo el más importante que suprime la limitación de su aplicación a los delitos que merezcan pena de crimen. Es decir ahora la norma se aplica a los tipos penales cualquiera sea su pena. Sin embargo, no afecta a la posibilidad del otorgamiento de la prisión preventiva en los casos que estamos analizando dado que los tres tipos penales contra la propiedad incluidos en el inciso segundo de artículo 149 tienen todos penas de crimen. 
nas a las que puede aplicarse el procedimiento abreviado. En consecuencia, aquellos que demanden el ejercicio de su derecho a un juicio deberán pagar un costo muy alto en términos del riesgo de una pena mayor. Lo más probable es que dada esta señal otorgada por la ley y los incentivos asociados, los actores amolden su conducta generando prácticas que abandonen cualquier desconfianza respecto del procedimiento abreviado y se orienten más bien a favorecerlo, reduciéndose por ejemplo las posibilidades de que los jueces indaguen sobre las motivaciones del acuerdo, sobre los méritos probatorios del caso y se reduzca la posibilidad de rechazo del procedimiento abreviado por parte del juez. Incluso es probable que los defensores asuman e integren a su practica la noción de que la negociación es un camino conveniente y aún los mismos imputados, especialmente aquellos con contactos frecuentes con el sistema entiendan que es así como este funciona y tiendan a olvidar la noción de que el juicio es la forma regular de resolución de los casos.

En consecuencia, es posible que en los próximos años podamos observar que tratándose de los delitos no regulados por la ley 20.931 se mantenga vigente una lógica de utilización limitada del procedimiento abreviado, donde se exprese la noción original del Código Procesal Penal que lo regula de manera más bien reticente a su utilización. En cambio, en los delitos incluidos en la nueva ley es muy probable que se genere una lógica diferente en que el juicio tienda a disminuir su presencia y el procedimiento abreviado tienda a constituirse en la forma rutinaria de funcionamiento del sistema.

En una sociedad democrática es normal y esperable que el proceso penal cambie en sus orientaciones ampliando o reduciendo las expresiones concretas de las garantías individuales. Los cambios en las expectativas de público, en las circunstancias de la criminalidad, en las diversas opciones ideológicas de los gobernantes, son, entre otros, factores que van modificando los diversos componentes de la justicia penal. Sin embargo, lo que es criticable es la aplicación diferenciada de una concepción ideológica de la justicia penal, en este caso destinada a evitar el juicio oral y sus garantías, a solo una parte de los delitos de que conoce el sistema, en especial cuando ellos tienden a ser cometidos por un segmento socialmente desfavorecido de la población. 


\section{Consideraciones finAlES}

Quizás el principal factor que contribuye a que las nociones ideológicas en competencia respecto a la justicia penal mantengan un cierto equilibrio en el terreno legislativo y de las definiciones de prioridades y lógicas de las instituciones está en el hecho de que, dada la amplitud de la definición de las conductas delictivas, miembros de todos los grupos sociales pueden ser a lo menos teóricamente objeto de la persecución penal. Si bien es cierto que la persecución penal suele recaer muy mayoritariamente sobre personas de los grupos relativamente más pobres y con menos influencia política y social, existen casos en que se persigue a personas de otros grupos e incluso ocasionalmente a algunos miembros de los sectores más influyentes. Esta circunstancia permite que cuando se toman las definiciones sobre el sistema de justicia penal todos los grupos y en especial los de mayor poder se vean obligados a tomar en cuanta, aunque sea de manera tenue, las nociones que aquí hemos caracterizado como vinculadas al modelo del debido proceso. Es decir el hecho de que todos podamos ser afectados por el sistema, aunque el riesgo sea muy diferente, contribuye a que este mantenga un cierto equilibrio básico.

En nuestra opinión la ley 20.931, siguiendo otras reformas anteriores, aunque menos significativas en cuanto a su impacto, ${ }^{21}$ ha venido a establecer una segmentación en nuestro sistema de justicia penal que rompe el principio de unidad del sistema y permite, en consecuencia, el desequilibrio del mismo. Es muy difícil imaginar una regulación del procedimiento abreviado como la que introduce esta ley, con los enormes incentivos para la renuncia al juicio si es que debiera aplicarse a todos los delitos, en especial a aquellos que pueden ser cometidos por personas que forman parte de los grupos sociales más poderosos.

Las ideas que hemos planteado sobre lo que hemos pretendido definir como un segmento diferenciado de nuestro sistema de justicia penal que es el constituido por los delitos de hurto y robo después de la ley 20.931 son prospectivas e hipotéticas. La sola existencia de una regulaci-

21 Existen otras modificaciones legales recientes que han introducido reglas especiales para la determinación de las penas para delitos específicos. Es el caso de la ley 20.770 relativa algunos delitos de la ley de tránsito y la 20.813 relativa a delitos de la ley de control de armas. Estas leyes son manifestaciones de la tendencia a la fragmentación de nuestro sistema de justicia penal y generan 
ón legal diferenciada no basta para definir que ese segmento responde a otro modelo ideológico puesto que para ello se requeriría que las prácticas profesionales, la comprensión de los operadores y el funcionamiento rutinario del sistema se orientara en el sentido inducido por la ley. La ocurrencia o no de un fenómeno semejante es algo que debe evaluarse en el futuro por medio de estudios empíricos y es posible pensar razones por las cuales dicho desarrollo puede verse fuertemente atenuado. Por ejemplo, cabe la posibilidad de que, frente a la necesidad de imponer penas más severas, los jueces aumenten las exigencias probatorias y tiendan a absolver una mayor proporción de casos. Eso disminuiría el poder negociador de los fiscales y consecuentemente no se produciría el efecto de disminución en el incentivo del imputado para pedir su derecho al juicio.

Pero, más allá de cómo se desarrolle en concreto el proceso de aplicación de la nueva ley pensamos que esta abre una perspectiva muy problemática, que es la de que continúe la dictación legislación para un segmento diferenciado del sistema de justicia penal continúe a nivel legislativo. Es decir, una vez que este se encuentra definido resulta mucho más fácil para el legislador dictar nuevas normas que, por ejemplo, corrijan cualquier resistencia que desde los actores del sistema se manifieste en cuanto a dar lugar a un sistema de sanciones rápidas mediante procedimiento abreviado para los delitos de Hurto y Robo.

\section{REFERENCIAS}

BAYTELMAN, Andres; DUCE, Mauricio. Litigación Penal y Prueba. Santiago: Universidad Diego Portales, 2004.

DEL RIO, Carlos. Proceso Penal consenso de las partes y enjuiciamiento jurisdiccional. Santiago: Librotecnia, 2009.

DUCE, Mauricio; RIEGO, Cristian. La Prisión Preventiva en Chile: Análisis de los cambios legales y su impacto.Santiago: Ediciones Universidad Diego Portales, 2011. FALCONE, Diego. La Absolución en el Procedimiento Abreviado. Revista de Derecho de la Pontificia Universidad Católica de Valparaíso, vol. XXVI, p. 363378, 2005.

serios problemas aunque no alcanzan el carácter estructural ni tienen en impacto cuantitativo de la ley 20.931 . 
HORVITZ, María Inés; LOPEZ, Julián. Derecho Procesal Penal Chileno.Tomo II. Santiago: Jurídica de Chile, 2014.

LANGER, Maximo. From Legal Transplants to Legal Translations: The globalization of Plea Bargaining and the Americanization Thesis in Criminal Procedure Trial. In: THAMAN, Stephen (ed.). World Plea Bargaining. Consensual Procedures and the Avoidance of the Full Criminal Trial. Durham: Carolina Academic Press, 2010. MAIER, Julio. Prologo. In: MAIER, Julio; BOVINO, Alberto (comps). El Procedimiento Abreviado. Buenos Aires: Del Puerto, 2001.

RIEGO, Cristián. El Procedimiento Abreviado. In: CAROCCA, Alex (org.). Nuevo Proceso Penal. Santiago: Jurídica Cono Sur, 2000.

RIEGO, Cristian. El Procedimiento Abreviado en Chile. In: MAIER, Julio B. J.; BOVINO, Alberto (comps.) El Procedimiento Abreviado. Buenos Aires: Del Puerto, 2001.

THAMAN, Stephen. A Typology of Consensual Criminal Procedure, an Historical and Comparative Perspective on the Theory and Practice of Avoiding the Full Criminal Trial. In: THAMAN, Stephen (ed.). World Plea Bargaining. Consensual Procedures and the Avoidance of the Full Criminal Trial. Durham: Carolina Academic Press, 2010.

VIAL, Pelayo. Técnicas y Fundamentos del Contraexamen en Proceso Penal Chileno. Santiago: Librotecnia, 2016.

\section{Informações adicionais e declarações dos autores (integridade científica)}

Declaração de conflito de interesses (conflict of interest declaration): o autor confirma que não há conflitos de interesse na realização das pesquisas expostas e na redação deste artigo.

Declaração de autoria (declaration of authorship): todas e somente as pessoas que atendem os requisitos de autoria deste artigo estão listadas como autores. O autor se responsabiliza integralmente pelo conteúdo total deste artigo.

Declaração de ineditismo e originalidade (declaration of originality): assegura-se que o texto aqui publicado não foi divulgado anteriormente em outro meio e que futura republicação somente se realizará com a indicação expressa da referência desta publicação original; também atesta-se que não há plágio de terceiros ou autoplágio. 


\section{Dados do processo editorial}

(http://www.ibraspp.com.br/revista/index.php/RBDPP/about/editorialPolicies)

- Recebido em: 11/04/2017

- Controle preliminar e verificação de plágio: 12/04/2017

- Retorno rodada de correções 1: 12/04/2017

- Avaliação 1: 25/05/2017

- Avaliação 2: 04/06/2017

- Avaliação 3: 07/06/2017

- Avaliação 4: 07/06/2017

- Decisão editorial preliminar: 08/06/2017

- Retorno rodada de correções 2: 12/06/2017

- Decisão editorial final: 13/06/2017

\section{Equipe editorial envolvida}

- Editor-chefe: 1 (VGV)

- Editora-associada: 1 (FMB)

- Revisores: 4

\section{COMO CITAR ESTE ARTIGO:}

RIEGO, Cristián. La renuncia a las garantías del juicio oral por medio del procedimiento abreviado en Chile. Revista Brasileira de Direito Processual Penal, Porto Alegre, vol. 3, n. 3, p. 825-847, set./dez. 2017. https://doi.org/10.22197/rbdpp.v3i3.80

\section{(c) (1) (\$)}

Esta obra está licenciada com uma Licença Creative Commons Atribuição-NãoComercial 4.0 Internacional. 